\title{
Assessment of Bacterial Contamination at the Time of Embryo Transfer, and its Impression on the In-Vitro Fertilization / Pregnancy Outcome, in Sana'a City, Yemen
}

\begin{abstract}
Abdullah AD Al-Rukeimi ${ }^{1,2}$, Nojood Ali Jamial ${ }^{3}$, Hassan A Al Shamahy ${ }^{3 *}$, Taghreed Hussein Al Falahi ${ }^{3}$, Ahmed Mohamed Al Hadad ${ }^{4}$ and Khaled Abdulkarim Al Moyed ${ }^{3}$
\end{abstract}

${ }^{1}$ Department of Obstetrics and gynecology, Saudi Hajjah Hospital, Hajjah city, Yemen

${ }^{2}$ Department of community Medicine, Faculty of Medicine and Health Sciences, Sana'a University, Yemen

${ }^{3}$ Department of Medical Microbiology and Clinical Immunology, Faculty of Medicine and Health Sciences, Sana'a University, Republic of Yemen

${ }^{4}$ Department of Medical Microbiology, Faculty of Medicine and Health Sciences, Hadhramout University, Republic of Yemen

*Corresponding author: Hassan A Al Shamahy, Faculty of Medicine and Heath Sciences, Sana'a University, P.O. Box 775 Sana'a, Yemen.
Received Date: April 08, 2019

Published Date: April 18, 2019

\section{Abstract}

Background: In spite of advances in the field of assisted reproductive techniques including in-vitro fertilization (IVF) and intra-cytoplasmic sperm injection (ICSI), the pregnancy rate remained low. One of the major events in fertility is implantation process. One of the most important negative factors affecting implantation and pregnancy outcome is introduction of normal flora or potential pathogens of vagina or cervical region into uterus during embryo transfer.

Objectives: This study was designed to determine the most contaminants bacteria and examine the effect of bacterial contamination on in-vitro fertilization treatment outcomes.

Methods: A prospective clinical trial was carried out during a period of 12 months, starting in October 2016 and ending in September 2017. 162 patients aged 23-38 years, mean 32.4 \pm 5.7 , undergoing IVF treatment were selected for this study. Catheter tip samples were collected poster embryo transfer, cut off and cultured to identify any bacteria present by bacterial standard methods.

Results: The pregnancy rate of the 162 studied women was 54.32\% (positive B-hcg) and $45.68 \%$ had pregnancy failure (negative B-hcg). The highest positive pregnancy rate occurred in age group 26-29 years (63\%). The most contaminants bacteria were Staphylococcus coagulase negative (21.4\%), Non-hemolytic streptococci (17.9\%), Pseudomonas aeruginosa (17.9\%) and E. coli (14.3\%). The pregnancy rates did not differ significantly between the positive and negative bacterial growth, but significant decreased pregnancy rate was observed in patients who are positive to Pseudomonas aeruginosa, and E. coli.

Conclusion: Bacterial colonization of the ET catheter tip particularly with Pseudomonas aeruginosa and E. coli is associated with a reduction in the clinical pregnancy rate. Usefulness of routine cervical swab; microscopy, culture, and sensitivity at preparation of patients for IVF-ET treatment is suggested.

Keywords: Bacterial contamination; Embryo transfer; IVF/ Pregnancy outcome; Sana'a Yemen

\section{Introduction}

In-vitro fertilization (IVF) has been established as a widespread treatment of infertility throughout the world. It is indicated as primary treatment in cases with male factor infertility, severe tubal disease, and moderate to severe endometriosis. It is also a treatment option for patients with advanced maternal age
(>35 years), poor ovarian reserve, unexplained infertility, and an ovulation that is resistant to simpler treatment modalities [1]. Approximately $50 \%$ of infertile couples will require treatment with some form of assisted reproduction technology in other to achieve pregnancy [1,2]. Despite this progress, the majority of IVF cycles still 
do not produce a viable pregnancy [2]. Despite significant progress in the assisted reproduction field, the implantation rate of replaced embryos remains low. This has largely been attributed to variables such as the patient's age, endometrial receptivity, embryo quality [3,4] and embryo transfer technique [5-7]. As IVF requires the placement of embryos into the uterine cavity using a catheter that passes through the cervix, the possibility of bacterial contamination during the embryo transfer procedure evidently exists but has been inadequately investigated. In fact, there is growing evidence that bacterial contamination of the uterine cavity following transcervical embryo-transfer can negatively affect the implantation rates and the pregnancy outcome. Such contamination can occur during embryo replacement through the tip of the embryo transfer catheter from various vaginal-cervical microorganisms [1,2,813]. It is proof that genital infections, particularly those caused by sexually transmitted microorganisms, are among the leading causes of infertility $[14,15]$. In fact, detection of the Chlamydia species in the endo-cervices of women undertaking IVF treatment has been associated with decreased implantation and decreased continuing pregnancy rates [16,17]. In addition, studies have shown that subjects who test negative for bacterial contamination have approximately $50 \%$ higher pregnancy rates than subjects who test positive for bacterial contamination resulting from the embryo transfer catheter tip. An increased risk of pregnancy loss prior to the sixth week of gestation was also reported in women with bacterial vaginosis (BV) going through in-vitro fertilization treatment $[18,19]$. The decrease in live birth rate following IVF in women with catheter tip contamination as well as in women with BV, may be caused by decreased conception rates, increased pregnancy loss, or both. Furthermore, studies have shown that pathogenic bacteria cultured from the tip of the catheter produce a detrimental effect on live birth rates [10-13]. The understanding of whether genital bacteria have a negative impact on conception could lead to the implementation of an effective intervention that can improve pregnancy and delivery outcomes. Thus, this study was designed to determine the most contaminants bacteria and examine the effect of bacterial contamination on in-vitro fertilization treatment outcomes.

\section{Subjects and Methods}

\section{Patient selection}

In a prospective clinical study, 162 patients aged 23-38 year, mean $32.4 \pm 4.6$, undertaking IVF treatment were registered as subjects. The clinical indications for IVF treatment were tubal factor, idiopathic infertility or sperm abnormalities. With the aim of limit additional factors (e.g., embryo quality and endometrium receptivity) that might affect the results, we selected only patients aged $\leq 38$ years with a morphologically normal uterus and at least two good quality embryos available for embryo transfer. Embryo transfer was performed by the same physician. All the participating women underwent a microbiological examination of vaginalcervical and urethral pathogenic microorganisms two months prior to IVF treatment. The patients who were positive for any pathogenic microorganism underwent a specific therapy and thereafter a post-therapeutic control was performed. All the women were negative for Chlamydia trachomatis infection and none of them exhibited clinical and microbiological sign of cervicitis or vaginitis. All patients underwent a standard down-regulation protocol for ovarian stimulation induction. Oocyte recovery was carried out $36 \mathrm{~h}$ after HCG administration and embryo transfer took place 48 hours following insemination. Semen cultures were performed 2 months prior to IVF treatment. The men with positive microbial growth were given antibiotic treatment; thus, all the men had negative semen cultures at the time of the IVF treatment.

\section{Culture collection and bacterial isolation}

Catheter tip samples were collected poster embryo transfer, cut off and cultured to broth media, then sub-cultured to proper solid media to identify any bacteria present by bacterial standard methods. The samples were considered positive when 50 colonies forming units per sample were recovered for single micro-organism. The patients were categorized on the basis of the presence of the predominant single microorganism in the examined samples.

\section{Statistical analysis}

The resulting data were statistically correlated to the pregnancy rates in both positive testing and negative-testing patients by calculation associated odds ratio (OR) and 95\% Confidence interval $(95 \% \mathrm{CI})$. For statistical analysis $\chi 2$ and test were used where appropriate. The differences were considered statistically significant when $\mathrm{p} \leq 0.05$.

\section{Ethical approval}

All patients were counseled about the nature of the study and gave their written informed consent. The study proposal was evaluated and approved by the Ethics Committee of Faculty of Medicine and Health Sciences, Sana'a University.

\section{Results}

The study results are described in 5 tables from Table 1 to Table 5. The pregnancy rate of the 162 studied women was $54.32 \%$ (positive B-hcg) and $45.68 \%$ had pregnancy failure (negative B-hcg). The highest positive pregnancy rate occurred in age group 26-29 years (63\%). The most contaminants bacteria were Staphylococcus coagulase negative (21.4\%), Non-hemolytic streptococci (17.9\%), Pseudomonas aeruginosa (17.9\%) and E. coli (14.3\%). The pregnancy rates did not differ significantly between the positive and negative bacterial growth, but significant decreased pregnancy rate was observed in patients who are positive to Pseudomonas aeruginosa and to E. coli.

Table 1: Age distribution of studied women who had In-Vitro fertilization, Sana'a city, Yemen.

\begin{tabular}{|c|c|c|}
\hline Age /Years & Number & $\%$ \\
\hline$<25$ & 40 & 24.7 \\
\hline $25-29$ & 54 & 33.3 \\
\hline $30-34$ & 50 & 30.9 \\
\hline$\geq 35$ & 18 & 11.1 \\
\hline Total & 162 & \\
\hline
\end{tabular}

Age range: $23-38$ years; Mean \pm SD: $32.4 \pm 5.7$ years 
Table 2: The association between pregnancy rate failure and age of studied women in Sana'a city Yemen.

\begin{tabular}{|c|c|c|c|c|c|c|c|c|}
\hline \multirow[t]{2}{*}{ Age/years } & \multicolumn{2}{|c|}{ Positive B-hcg } & \multicolumn{2}{|c|}{ Negative B-hcg } & \multirow{2}{*}{ OR } & \multirow{2}{*}{ CI } & \multirow{2}{*}{$\chi 2$} & \multirow{2}{*}{$\mathbf{P}$} \\
\hline & No. & $\%$ & $\%$ & NO. & & & & \\
\hline$<25$ & 20 & 50 & 20 & 50 & 0.79 & $0.3-1.6$ & 0.39 & 0.52 \\
\hline $25-29$ & 34 & 63 & 20 & 37 & 1.7 & 0.8-3.3 & 2.4 & 0.11 \\
\hline $30-34$ & 24 & 48 & 26 & 52 & 0.69 & $0.35-1.3$ & 1.6 & 0.28 \\
\hline $35-38$ & 10 & 55.6 & 8 & 44.4 & 1.1 & $0.39-2.8$ & 0.01 & 0.9 \\
\hline Total & 88 & 54.32 & 74 & 45.68 & & & & \\
\hline
\end{tabular}

B-hcg: Beta-human chorionic gonadotrophin; OR: Odds ratio < 1 (at risk); Cl: Confidence Interval; $x 2$ : Chi Squire $\geq 3.9=$ significant; P: Probability value $<0.05=$ significant.

Table 3: The association between pregnancy rate failure and positive growth culture of bacteria from the tip of catheter at the time of embryo transfer.

\begin{tabular}{|c|c|c|c|c|c|c|}
\hline \multirow[t]{2}{*}{ B-hcg } & $\begin{array}{l}\text { Positive growth } \\
\text { culture }\end{array}$ & & \multirow[t]{2}{*}{ OR } & \multirow[t]{2}{*}{$\mathrm{CI}$} & \multirow[t]{2}{*}{$x^{2}$} & \multirow[t]{2}{*}{$P$} \\
\hline & NO. & $\%$ & & & & \\
\hline Positive & 30 & 34.1 & 0.95 & $0.49-1.8$ & 0.01 & 0.88 \\
\hline \multicolumn{7}{|l|}{$\mathrm{N}=88$} \\
\hline Negative & 26 & 35.1 & 1 & 0.5 & 0.01 & 0.88 \\
\hline \multicolumn{7}{|l|}{$\mathrm{N}=74$} \\
\hline Total & 56 & 34.6 & & & & \\
\hline
\end{tabular}

B-hcg: Beta-human chorionic gonadotrophin; OR: Odds ratio < 1 (at risk); Cl: Confidence Interval; $X 2$ : Chi Squire $\geq 3.9=$ significant; P: Probability value $<0.05=$ significant.

Table 4: The frequency of micro-organisms isolated from the tip of catheter at the time of embryo transfer.

\begin{tabular}{|c|c|c|}
\hline Microorganism isolated & Number No. $\mathbf{5 6}$ & $\mathbf{6}$ \\
\hline Total Gram-positive Bacteria & 34 & 7.1 \\
\hline Staphylococcus aureus & 4 & 21.4 \\
\hline Staphylococcus coagulase negative & 12 & 17.9 \\
\hline Non - Hemolytic Streptococcus & 10 & 14.3 \\
\hline Enterococcus species & 8 & 39.3 \\
\hline Total Gram-negative Bacteria & 22 & 17.9 \\
\hline Pseudomonas aeruginosa & 10 & 3.5 \\
\hline Klebsiella species & 2 & 14.3 \\
\hline Escherichia coli & 8 & 3.5 \\
\hline Enterobacter species & 2 & \\
\hline
\end{tabular}

Table 5: The association between pregnancy rate failure and single positive growth culture of bacteria from the tip of catheter at the time of embryo transfer.

\begin{tabular}{|c|c|c|c|c|c|c|}
\hline Type of bacterial isolates & Negative B-hcg & & OR & CL & $\chi^{2}$ & $\mathrm{P}$ \\
\hline & NO & $\%$ & & & & \\
\hline Staphylococcus aureus $\mathrm{n}=4$ & 2 & 50 & 5.5 & $0.7-41$ & 3.5 & 0.06 \\
\hline $\begin{array}{c}\text { Staphylococcus coagulase } \\
\text { Negative } \mathrm{n}=12\end{array}$ & 2 & 16.7 & 1.1 & $0.25-5.1$ & 0.003 & 0.95 \\
\hline $\begin{array}{l}\text { Non - Hemolytic- } \\
\text { Streptococci } \mathrm{n}=10\end{array}$ & 4 & 40 & 3.9 & $1-15$ & 4.5 & 0.03 \\
\hline $\begin{array}{c}\text { Pseudomonas aeruginosa } \\
\mathrm{n}=10\end{array}$ & 8 & 80 & 29.7 & $5.8-151$ & 32 & $<0.001$ \\
\hline Escherichia coli $\mathrm{n}=8$ & 8 & 100 & 8.5 & $5.5-13$ & 44 & $<0.001$ \\
\hline Enterococci species $\mathrm{n}=8$ & 2 & 25 & 1.8 & $0.3-9.4$ & 0.5 & 0.47 \\
\hline Enterobacter species $\mathrm{n}=2$ & 0 & 0 & undefined & & & \\
\hline Klebsiella species $\mathrm{n}=2$ & 0 & 0 & undefined & & & \\
\hline Total $n=56$ & 26 & 35.1 & 1.6 & $0.82-3.2$ & 2.02 & 0.15 \\
\hline
\end{tabular}

B-hcg: Beta-human chorionic gonadotrophin; OR: Odds ratio < 1 (at risk); Cl: Confidence Interval; $X 2$ : Chi Squire $\geq 3.9=$ significant; P: Probability value $<0.05=$ significant 


\section{Discussion}

In vitro fertilization (IVF) is a process by which egg cells are fertilized by sperm outside the womb, in vitro. IVF is a major treatment in infertility when other methods of assisted reproductive technology have failed. The process involves hormonally controlling the ovulatory process, removing ova (eggs) from the woman's ovaries and letting sperm fertilize them in a fluid medium. The fertilized egg (zygote) is then transferred to the patient's uterus with the intent to establish a successful pregnancy. During recent years, in Yemen, Health care authorities as well as community are widely increasingly concerned (used) In vitro fertilization (IVF) as a major treatment in infertility when other methods of assisted reproductive technology have failed. Such widely used is well reflected in conducted this study, in our opinion this emerging issue should be more extensively discussed in medical community in Yemen, due to the costs of the procedure, and lost if these expensive options have failed.

For IVF to be successful it may be easier to say that it requires healthy ova, sperm that can fertilize, and a uterus that can maintain a pregnancy. Due to the costs of the procedure, IVF is generally attempted only after less expensive options have failed. Our study reported pregnancy rate of $54.3 \%$ (Table 2). This successful rate was lower than that reported by de La Rochebrochard et al. study which estimated that $66 \%$ of patients starting IVF treatment finally succeed in having a child [20]. Also, our positive B-hcg rate was higher than Papanikolaou et al. study which reported a pregnancy rate of $35 \%$ [21]. Female age is a major determinant of the success rate of infertility treatment and was the first recognized prognostic factor in IVF/ICSI. In our study the highest success rate was in age group 25-29 years group (63\%). This result is similar to that reported from Finland and USA in which the highest rate of success was occurred for med and late twenties women [22].

There was correlation between isolation of pathogenic bacteria that introduced from cervical region into uterus during embryo transfer and higher rate of failure of pregnancy for example positive culture of Pseudomonas aeruginosa have associated odds ratio of inhibitory effect on implantation equal to 29.7 times, with $\mathrm{CI}=5.8-15, \mathrm{X} 2=32, \mathrm{p}<0.001$. In other words, implantation rates in patients with and without cervical P. aeruginosa infection were $20 \%$ and $80 \%$, respectively (Table 5). Also, our study showed that, potentially pathogenic bacteria as $E$. coli in endo-cervix of women with unsuccessful implantation is more prevalent than those with successful implantation with risk of failure equal to 8.5 times $(p<0.001)$. Therefore, the results of this study imply the negative effects of cervical bacteria on the implantation process particularly with E. coli and Pseudomonas aeruginosa.

In addition, limited studies conducted about prevalence of bacterial genus or species that linked with high rate of pregnancy failure after in vitro fertilization (IVF). While there was highly significant association between negative B-hcg (pregnancy failure) and contamination the head of transferred catheter with E.coli and Pseudomonas aeruginosa. The current result is different from that reported by Aflatoonian and Asgharnia [23], and Veleva [22] in which they not reported bacterial vaginosis or contamination the head of transferred catheter with vaginal flora even with potential pathogenic bacteria as P. aeruoginosa and E.coli is one of factors that affecting pregnancy and implantation rates or on other words factor that principal to pregnancy failure after IVF. On other hand Liversedge et.al [19] reported the highly significant association between negative B-hcg (pregnancy failure) and contamination the head of transferred catheter with chlamydia trachomatus.

In our study there was no significant association between negative B-hcg (pregnancy failure) and contamination the head of transferred catheter with S.aureus or staphylococcus coagulase negative (Table 5). This result is different from that reported by Fotouh and Al-Inany [24], where they found a significant association between positive for Staphylococcus species with significant decreased pregnancy rate $(\mathrm{p}<0.001)$. Furthermore, in our study there was no significant association between pregnancy failure and contamination the head of transferred catheter with Enterococcus species (Table 5). This result is different from that reported by Eckert et al. [25] where they found a significant association between positive for Enterococcus species with significant decreased pregnancy rate $(\mathrm{p}<0.05)$.

\section{Conclusion}

Bacterial colonization of the ET catheter tip particularly with Pseudomonas aeruginosa, and E. coli is associated with a reduction in the clinical pregnancy rate. Usefulness of routine cervical swab; microscopy, culture, and sensitivity at preparation of patients for IVF-ET treatment is suggested.

\section{Acknowledgment}

Authors acknowledge the financial support of Sana'a University, in Sana'a city Yemen.

\section{Conflict of Interest}

No conflict of interest associated with this work.

\section{References}

1. Maduka RN, Osaikhuwuowan JA, Aziken ME (2018) The effect of bacterial colonization of the embryo transfer catheter on outcome of IVF-Embryo transfer treatment. Afr J Med Health Sci 17: 7-13.

2. Roseboom TJ, Vermeiden JPW, Schoute E, Lens JW, Schats R (1995) The probability of pregnancy after embryo transfer is affected by the age of the patient, cause of infertility, number of embryos transferred and the average morphology score, as revealed by multiple logistic regression analysis. Hum Reprod 10(11): 3035-3041.

3. Schoolcraft W, Meseguer M (2017) Paving the way for a gold standard of care for infertility treatment: Improving outcomes through standardization of laboratory procedures. Reprod Biomed Online 35(4): 391-399.

4. Javed M, Al Sufyan H, Salih A, Najashi S (2017) Important female factors affecting success in assisted reproductive technology procedures. Women Health Sci J: 1:000107.

5. Rabiee S, Kaboodmehri R, Fallah M, Yavangi M, Farimani MS (2013) Effect of cervical mucus aspiration before embryo transfer on pregnancy rate. Iran J Reprod Med 11(1): 849-850.

6. Efiok EE, Udoh AE, Iyang-Out A (2012) Study of the bacterial flora of the vaginal and cervix in women of childbearing age in rural community of Niger Delta Region, Nigeria. Gynecol Obstet: 2:1000108. 
7. Ikechebelu JI, Eleje GU, Ibadin K, Joe-Ikechebelu NN, Nwaefulu K, et al (2016) Outcome of in vitro fertilization procedure at a private fertility centre in Nnewi South East Nigeria. Afr J Infertil Assist Concept 1(1): 2-5.

8. Karande VC, Morris R, Chapman C, Rinehart J, Gleicher N (1999) Impact of the "physician factor" on pregnancy rates in a large assisted reproductive technology program: Do too many cooks spoil the broth? Fertil Steril 71(6): 1001-1009.

9. Hearns-Stokes RM, Miller BT, Scott L, Creuss D, Chakraborty PK, et al. (2000) Pregnancy rates after embryo transfer depend on the provider at embryo transfer. Fertil Steril 74(1): 80-86.

10. Egbase PE, Al-Sharhan M, Al-Othman S, Al-Mutawa M, Udo EE, et al. (1996) Incidence of microbial growth from the tip of embryo transfer catheter after embryo transfer in relation to clinical pregnancy rate following in-vitro fertilization and embryo transfer. Hum Reprod 11(8): 1687-1689.

11. Egbase PE, Udo EE, Al-Sharhan M, Grudzinskas JG (1999) Prophylactic antibiotics and endocervical microbial inoculation of the endometrium at embryo transfer (letter). Lancet 354(9179): 651-652.

12. Fanchin R, Harmas A, Benaoudia F, Lundkvist U, Olivennes F, et al. (1998) Microbial flora of the cervix assessed at the time of embryo transfer adversely affects in vitro fertilization outcome. Fertil Steril 70(5): 866870 .

13. Moore DE, Soules MR, Klein NA, Fujimoto VY, Agnew KJ, et al. (2000) Bacteria in the transfer catheter tip influence the live-birth rate after in vitro fertilization. Fertil Steril 74(6): 1118-1124.

14. Weström L (1975) Effect of acute pelvic inflammatory disease on fertility. Am J Obstet Gynecol 121(5): 707-713.

15. Faro S (1991) Chlamydia trachomatis: female pelvic infection. Am J Obstet Gynecol 164 (6 Pt 2): 1767-1770.

16. Witkin SS, Sultan KM, Neal GS, Jeremias J, Grifo JA, et al. (1994) Unsuspected Chlamydia trachomatis infection and in vitro fertilization outcome. Am J Obstet Gynecol 171(5): 1208-1214.
17. Witkin SS, Kligman II, Grifo JA, Rosenwaks Z (1995) Chlamydia trachomatis detected by polymerase chain reaction in cervices of culture-negative women correlates with adverse in vitro fertilization outcome. J Infect Dis 171(6): 1657-1659.

18. Ralph SG, Rutherford AJ, Wilson JD (1999) Influence of bacterial vaginosis on conception and miscarriage in the first trimester: cohort study. BMJ 319: 220-223

19. Liversedge NH, Turner A, Horner PJ, Keay SD, Jenkins JM, et al. (1999) The influence of bacterial vaginosis on in-vitro fertilization and embryo implantation during assisted reproduction treatment. Hum Reprod 14(9): 2411-2415.

20. de La Rochebrochard E, Thonneau P (2003) Paternal age >or=40 years: an important risk factor for infertility. Am J Obstet Gynecol 189(4): 901905.

21. Papanikolaou EG, Pozzobon C, Kolibianakis EM, Camus M, Tournaye $\mathrm{H}$, et al. (2006) Incidence and prediction of ovarian hyperstimulation syndrome in women undergoing gonadotropin-releasing hormone antagonist in vitro fertilization cycles. Fertil Steril 85(1): 112-120.

22. Veleva Z, Tiitinen A, Vilska S, Hydén-Granskog C, Tomás C (2008) High and low BMI increase the risk of miscarriage after IVF/ICSI and FET. Human Reproduction 23(4): 878-884.

23. Aflatoonian A, Asgharnia M (2006) Factors affecting the successful embryo transfer. Iranian Journal of Reproductive Medicine 4(2): 45-50.

24. Fotouh IA, Al-Inany MG (2008) The levels of bacterial contamination of the embryo transfer catheter relate negatively to the outcome of embryo transfer. Middle East Fertility Society Journal 13(1): 39-43.

25. Eckert LO, Moore DE, Patton DL, Agnew KJ, Eschenbach DA (2003) Relationship of vaginal bacteria and inflammation with conception and early pregnancy loss following in-vitro fertilization. Infect Dis Obstet Gynecol 11(1): 11-17. 